\title{
Penerapan Augmented Reality Berbasis Android untuk Pembelajaran Organ Lambung Manusia
}

\section{(Application of Android Based Augmented Reality for Human Stomach Organ Learning)}

\author{
Fony Ferliana Widianingrum ${ }^{1}$, Sugondo Hadiyoso ${ }^{2}$, Suci Aulia ${ }^{3}$
}

\begin{abstract}
The stomach is one of the digestive systems functioning as a medium to process and store food, as well as to get rid of harmful substances and absorb good substances for the body. Although elementary schools usually use the torso as a teaching aid to introduce the stomach organ, it is, in fact, very inflexible for elementary students as they have limited learning hours at school. Therefore, it is necessary to develop a stomach organ learning system that can be studied anytime and anywhere. In this study, an Android-based stomach organ learning application was designed by applying Augmented Reality (AR). To run this application, the user needs to install it first. After opening the application and selecting the desired menu, users can point the smartphone at the appropriate marker until the AR display appears. Based on the test results, the application cannot bring AR objects from the stomach organ in a dark place since the marker is not detected. The best distance for marker detection is $20 \mathrm{~cm}$ to $35 \mathrm{~cm}$, with an average delay of $0.3 \mathrm{~s}$ in indoor conditions and $0.45 \mathrm{~s}$ in outdoor conditions.
\end{abstract}

Intisari-Lambung merupakan salah satu sistem pencernaan yang berfungsi sebagai media pengolah dan penyimpanan makanan, serta untuk menyingkirkan zat berbahaya dan menyerap zat baik bagi tubuh. Biasanya, sekolah dasar menggunakan torso sebagai alat bantu peraga organ lambung. Namun, hal ini sangat tidak fleksibel bagi siswa sekolah dasar yang memiliki keterbatasan jam belajar di sekolah. Oleh karena itu, perlu dikembangkan suatu sistem pembelajaran organ lambung yang dapat dipelajari kapan saja dan di mana saja. Pada makalah ini dirancang suatu aplikasi pembelajaran organ lambung berbasis Android dengan menerapkan Augmented Reality (AR). Untuk menjalankannya, pengguna perlu menginstal aplikasi terlebih dahulu, kemudian membuka aplikasi, memilih menu yang diinginkan, lalu mengarahkan smartphone ke arah marker yang sesuai sampai tampilan AR muncul. Berdasarkan hasil pengujian, aplikasi tidak dapat memunculkan objek AR dari organ lambung pada tempat yang gelap karena marker tidak terdeteksi. Jarak terbaik untuk deteksi marker yaitu pada rentang jarak $20 \mathrm{~cm}$ sampai $35 \mathrm{~cm}$, dengan rata-rata delay $0,3 \mathrm{~s}$ pada kondisi indoor dan $0,45 \mathrm{~s}$ pada kondisi outdoor.

Kata Kunci-Stomach, Augmented Reality, Android, Marker.

\section{Pendahuluan}

Lambung adalah bagian saluran makanan yang berbentuk seperti kantong dan berfungsi sebagai tempat penampungan,

1,2,3 Universitas Telkom, Jl. Telekomunikasi No. 1, Dayeuh Kolot Bandung 40257 INDONESIA (tlp: 022-7565930; e-mail: 1fonyferliana17@gmail.com,_2sugondo@telkomuniversity.ac.id, ${ }^{3}$ suciaulia@telkomuniversity.ac.id) pelarutan, dan pencernaan makanan. Lambung merupakan salah satu bagian dari organ pencernaan yang bekerja mencerna makanan kurang lebih tiga sampai empat jam atau tergantung jenis makanan yang masuk ke dalam tubuh. Pembelajaran mengenai organ tubuh manusia didapatkan di sekolah dengan menggunakan torso dan buku sebagai medianya. Meskipun pembelajaran menggunakan torso lebih nyata daripada buku, tetapi torso hanya dapat dipakai di sekolah, sehingga siswa sekolah dasar (SD) harus menunggu hari esok untuk menggunakannya. Seperti yang sudah diketahui, Android telah menguasai bidang teknologi, misalnya pada smartphone. Perkembangan teknologi smartphone dimanfaatkan sebagian orang untuk membuat suatu media pembelajaran berbasis Augmented Reality (AR) [1]. Pengguna (user) hanya membutuhkan benda pendukung seperti smartphone Android, marker, dan aplikasi pendukung AR [2], [3]. Dalam kehidupan sehari-hari, AR sudah mulai mendominasi pasar dunia [4]. Beberapa penelitian telah menggunakan AR untuk memvisualisasikan sebuah objek, seperti pengenalan pola emosi wajah [5], 3D foot phantom [6], smart home control [7], sistem informasi pada smart building [8], media informasi bank baterai [9], dan M-Commerce [10].

Selain implementasi tersebut, AR mulai digunakan sebagai sarana pembelajaran di bidang pendidikan [11]. Sebagai contoh, ARca merupakan buku yang menyediakan fasilitas tambahan dengan program AR [12]. Penelitian lainnya berbasis AR adalah metode pembelajaran siklus air berbasis AR [13] dan sistem pembelajaran kasus sistem koordinat berbasis AR [14]. Penelitian lainnya yang memanfaatkan AR untuk menunjang sistem pembelajaran organ tubuh manusia di antaranya menggunakan monitor sebagai visualisasi dan keyboard untuk memilih opsi yang telah disediakan [15] dan mengaplikasikan AR untuk mempelajari anatomi mata [16]. Berdasarkan penelitian-penelitian di atas, pada makalah ini dibuat suatu aplikasi pembelajaran berbasis Android yang berfokus pada organ pencernaan lambung. Organ pencernaan lambung dipilih karena hasil kuesioner menyebutkan sebanyak $85,7 \%$ responden dari total 91 responden memilih untuk membahas organ lambung.

Dengan adanya aplikasi pembelajaran lambung manusia yang mengusung teknologi AR ini, siswa SD dapat memahami pelajaran mengenai organ pencernaan lambung, sehingga dapat mempermudah para guru menyampaikan informasi kepada anak didiknya. Terlebih lagi, zaman yang semakin maju akan terus menuntut manusia mengikuti perkembangannya dari hari ke hari. Dengan memanfaatkan aplikasi ini, siswa SD dapat lebih mudah mengakses informasi yang dibutuhkan. 


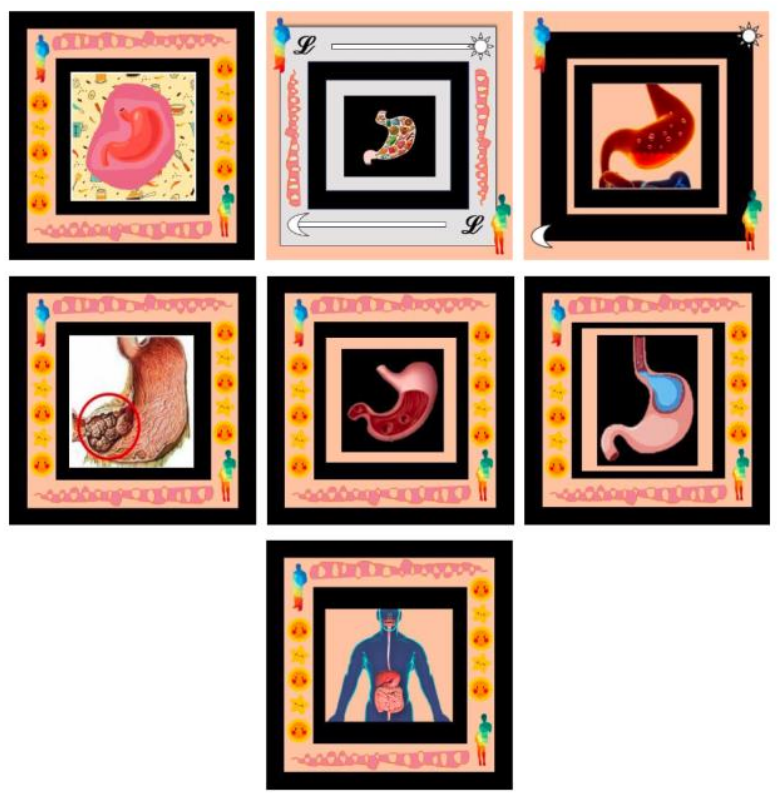

Gbr. 1 Keenam marker yang digunakan pada aplikasi pembelajaran organ lambung.

\section{MATERI}

\section{A. Marker}

Marker adalah penanda khusus yang diracang untuk memunculkan target [17]. Marker di sini memiliki bentuk pola unik sebagai pembeda dengan marker lainnya. Keunikan pola tersebut akan sangat berpengaruh dalam proses scanning. Marker seperti yang ditunjukkan pada Gbr. 1 ini berfungsi sebagai penanda objek yang posisi dan penampilannya sudah dikenali oleh sistem selama masa scanning [18].

\section{B. Augmented Reality (AR)}

AR adalah objek 3D yang akan keluar ketika brosur atau pattern dipindai oleh software [19]. Pembuatan objek dapat dilakukan menggunakan berbagai macam software modeling 3D. Penggunaan AR dapat memunculkan benda virtual secara nyata dan diproyeksikan secara real-time [20]. Gbr. 2 menunjukkan ilustrasi AR dari lambung manusia. Adapun beberapa aplikasi yang dibutuhkan untuk mendukung pembuatan AR adalah sebagai berikut [9].

1) Blender: Blender merupakan sebuah software yang digunakan untuk membuat desain 3D. Software Blender dapat diunduh secara gratis melalui website resminya. Project kerja pada Blender dapat dikerjakan di hampir semua software 3D komersial lainnya. Pengguna hanya perlu mengubah atau mengekspor ke dalam format software masing-masing.

2) Vuforia: Vuforia merupakan plugin dari software $3 \mathrm{D}$ Unity. Untuk membuat aplikasi AR, dibutuhkan beberapa komponen objek dasar model 3D. Dalam Vuforia terdapat dua develop, yaitu Licence Manager dan Target Manager. Licence Manager dibuat agar pengguna mendapatkan licence key yang berguna untuk menunjang basis data pada pembuatan aplikasi, sedangkan Target Manager dibuat untuk memasukkan basis data marker yang akan dibuat.

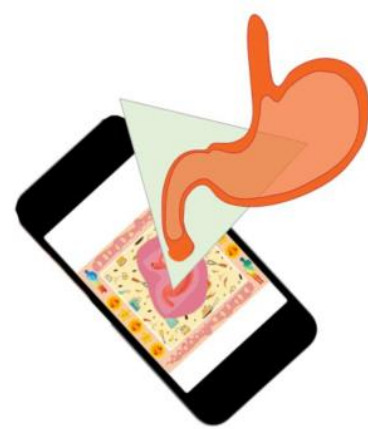

Gbr. 2 AR dari organ lambung.

3) Unity: Unity merupakan sebuah game engine yang dapat membuat game 2D atau 3D. Kelebihan utama Unity adalah dapat diunduh secara gratis dan berisi asset store atau perlengkapan yang dapat langsung digunakan. Asset yang tersedia antara lain bentuk karakter dan script.

\section{Lambung}

Lambung adalah organ berbentuk $\mathbf{J}$ yang letaknya berada di kuadran kiri atas perut atau abdomen. Bagian tepi atasnya terhubung langsung dengan esofagus yang berada di bawah diafragma. Batas bawah organ lambung yang terletak di sebelah kanan garis tengah menyatu dengan duodenum. Ukuran lambung bervariasi, tergantung pada volume makanan yang ada [21]. Organ lambung berperan penting untuk menyimpan dan mencerna baik makanan maupun minuman yang masuk ke dalam tubuh manusia, sehingga sangat penting untuk dijaga.

\section{Penyakit Lambung}

Organ lambung yang tidak dapat bekerja secara normal dapat menyebabkan beberapa penyakit seperti sebagai berikut [22].

1) Gastroesophageal Reflux Disease (GERD): Gastroesophageal Reflux Disease (GERD) terjadi karena terdapat kelainan yang disebabkan oleh naiknya cairan lambung ke kerongkongan. Akibatnya, penderita GERD akan merasakan gejala rasa panas seperti terbakar pada dada bahkan leher. Selain itu, gejala lainnya yang timbul adalah sulit menelan karena infeksi pada kerongkongan serta rasa pahit di lidah.

2) Mag: Kondisi ini terjadi karena terdapat luka maupun peradangan pada lambung yang disebabkan oleh jumlah asam klorida atau hydrochloric acid $(\mathrm{HCl})$ yang berlebihan.

3) Kanker Lambung: Berbeda dengan mag, kanker lambung disebabkan oleh pertumbuhan sel lambung yang berlebihan atau bahkan tak terkendali. Kanker lambung juga dapat terjadi karena faktor genetik.

\section{ARSITEKTUR DAN PERANCANGAN SISTEM}

\section{A. Diagram Blok Sistem Aplikasi Pembelajaran Organ Lambung}

Diagram blok sistem aplikasi pembelajaran organ lambung diperlihatkan pada Gbr. 3. Terdapat dua bagian dalam sistem kerja aplikasi ini. Berikut adalah tahapan dari proses tersebut. 


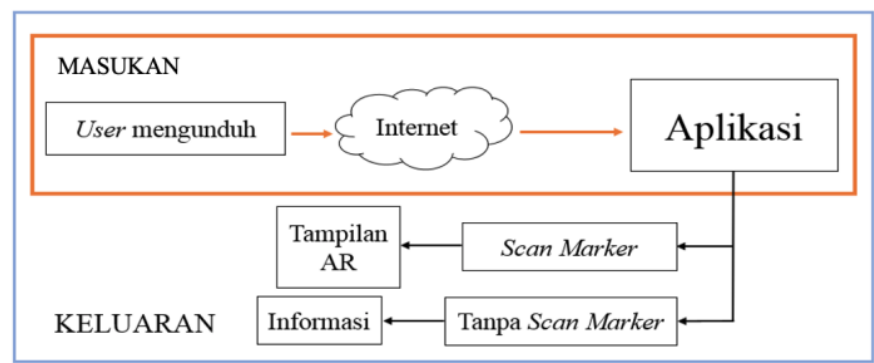

Gbr. 3 Diagram blok sistem aplikasi pembelajaran organ lambung.

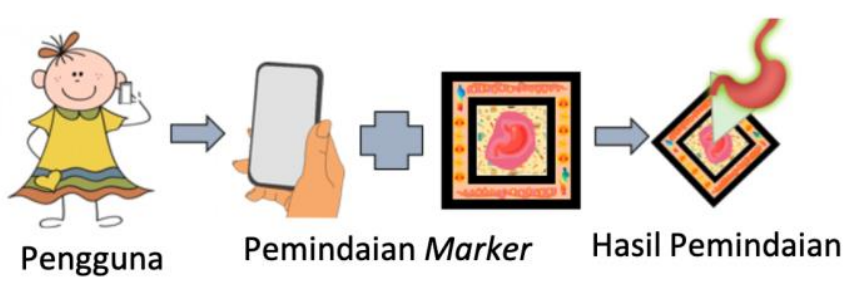

Gbr. 4 Diagram ilustrasi proses pemindaian atau scanning pada marker.

1) Masukan: Pada bagian ini, pengguna mengunduh aplikasi dan masuk tanpa melakukan login terlebih dahulu. Dengan mengakses aplikasi ini, pengguna dapat menjalankan aplikasi sesuai perintah yang diinginkan.

2) Keluaran: Pada bagian ini, data yang telah diproses akan ditampilkan menggunakan marker dan tanpa menggunakan marker. Maksud dari menggunakan marker adalah data muncul ketika kamera melakukan scanning pada marker, sedangkan tanpa marker berarti data akan ditampilkan tanpa harus melakukan proses scanning marker.

Gbr. 4 merupakan alur untuk menjalankan aplikasi pembelajaran organ lambung berbasis AR. Untuk menjalankannya, pengguna perlu mengunduh dan menginstal aplikasi yang telah disediakan. Kemudian, pengguna membuka aplikasi dan memilih menu yang diinginkan, lalu mengarahkan smartphone ke marker yang sesuai. Setelah beberapa saat, akan muncul tampilan AR.

\section{B. Alur Kerja Sistem Aplikasi Pembelajaran Organ Lambung}

Berikut adalah alur kerja aplikasi pembelajaran organ lambung.

1) Diagram Alir Sistem Aplikasi Pembelajaran Organ Lambung: Diagram alir sistem aplikasi pada Gbr. 5 menjelaskan aktivitas yang dapat dilakukan oleh pengguna ketika menggunakan aplikasi ini. Terdapat dua menu utama, satu menu About Us, dan satu menu keluar yang tersedia dalam aplikasi. Aplikasi dimulai ketika pengguna memilih menu Mulai. Setelah memilih menu Mulai, pengguna masuk pada menu Home dan dihadapkan dengan beberapa pilihan fitur. Pengguna dapat memilih menu Scan jika ingin melihat bentuk lambung dan melihat informasi mengenai lambung. Pengguna juga dapat memilih menu Quiz, yang berisi beberapa soal yang dapat dikerjakan oleh pengguna. Setelah pengguna selesai menyelesaikan semua soal, akan muncul kondisi mengulangi soal dan kondisi keluar dari menu Quiz, yaitu pengguna langsung kembali ke menu utama. Tombol "x" yang terdapat

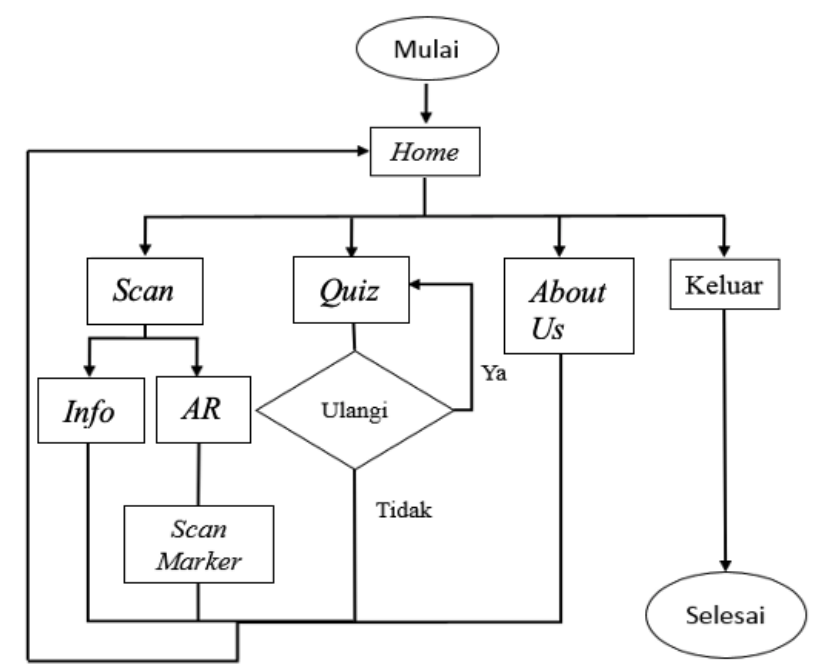

Gbr. 5 Diagram alir sistem aplikasi pembelajaran organ lambung.

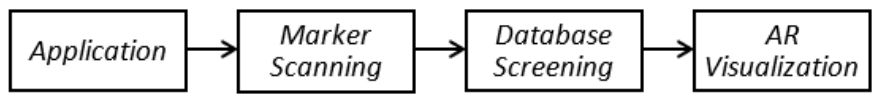

Gbr. 6 Diagram blok sistem pembacaan marker.

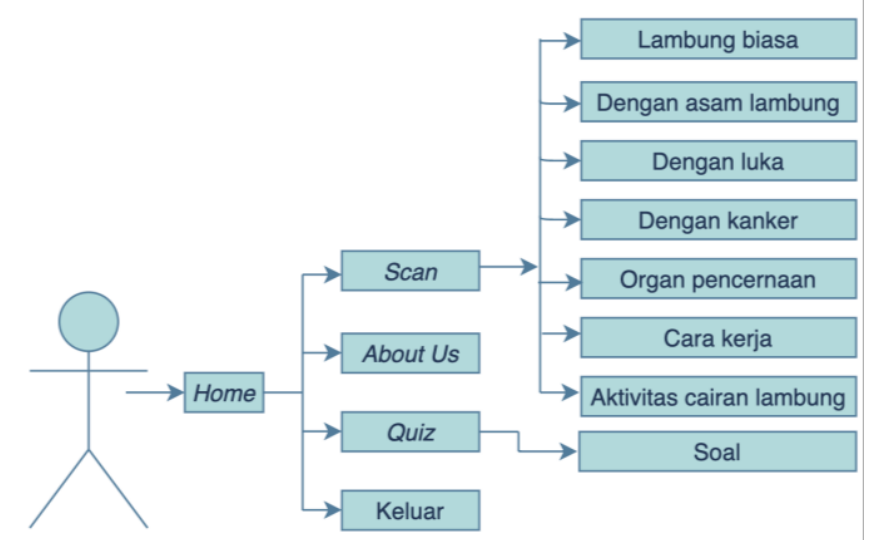

Gbr. 7 Perancangan menu aplikasi pembelajaran organ lambung

pada pojok kanan atas aplikasi digunakan untuk keluar dari aplikasi.

2) Diagram Blok Sistem Pembacaan Marker: Scanning atau deteksi marker diperlukan agar objek AR dapat ditampilkan. Proses ini membutuhkan marker yang telah didaftarkan atau dimasukkan ke basis data Vuforia sebelumnya. Jika marker yang dideteksi tidak sesuai, gambar yang diinginkan tidak dapat dimunculkan. Pada Gbr. 6 ditunjukkan diagram blok sistem pembacaan marker. Proses pada Gbr. 6 dilakukan agar tampilan AR muncul. Setiap marker mempunyai basis data tersendiri pada Vuforia. Adapun perancangan tampilan menu dan submenu dari aplikasi pembelajaran lambung manusia ditunjukkan pada Gbr. 7.

Dalam penggunaan aplikasi ini, diperlukan beberapa tahapan, yaitu:

- pengguna masuk ke menu utama atau Home; dan

- setelah masuk pada menu Home, ada beberapa pilihan menu yang harus dipilih oleh pengguna. 


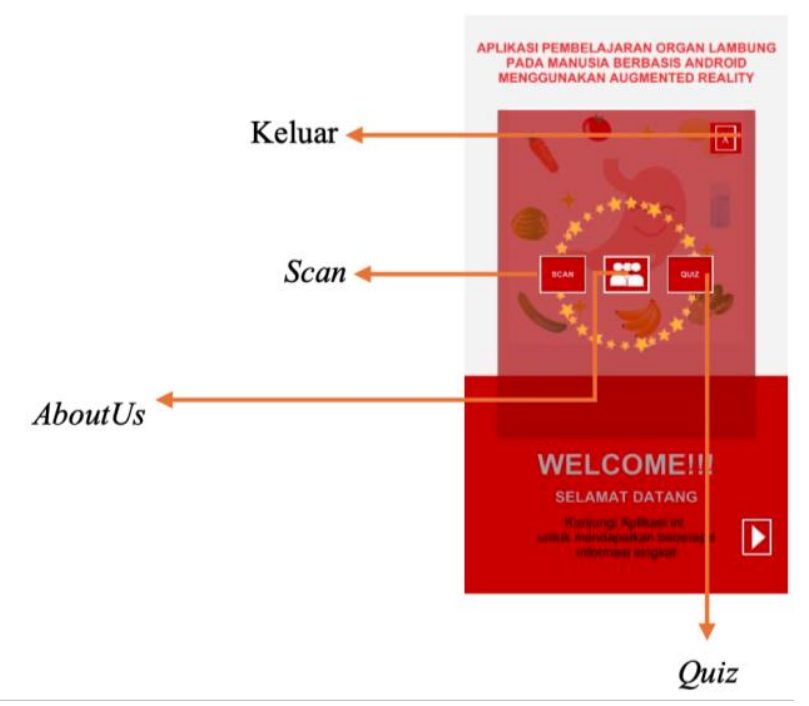

Gbr. 8 Antarmuka menu Home.

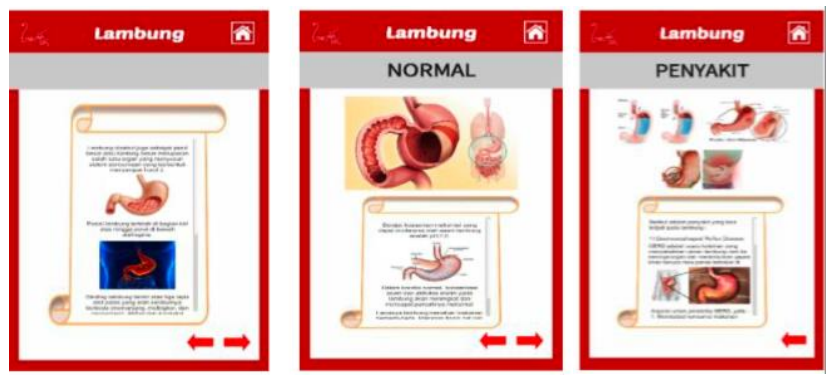

Gbr. 9 Tampilan aplikasi pembelajaran objek lambung.

Setelah pengguna membuka aplikasi yang telah terpasang pada smartphone Android, sistem dapat menampilkan menumenu aplikasi. Ketika pengguna memilih salah satu menu yang tersedia, kamera akan menampilkan objek dalam bentuk AR dengan cara mengarahkan kamera ke marker yang sesuai, sehingga sistem dapat mendeteksi marker yang telah dibuat dan didaftarkan pada basis data Vuforia.

\section{Antarmuka Sistem Aplikasi}

Antarmuka aplikasi yang telah dibuat ditunjukkan pada Gbr. 8. Pada menu Home ditampilkan beberapa pilihan menu yang tersedia dalam aplikasi, yaitu menu Scan, Quiz, About Us, dan Keluar. Beberapa tampilan dari aplikasi yang menjelaskan pengertian lambung, stuktur lambung, dan penyakit lambung ditunjukkan pada Gbr. 9.

\section{IV.PENGUJIAN DAN ANALISIS}

\section{A. Pengujian Fungsionalitas}

Pengujian fungsionalitas ini ditujukan untuk mengetahui tingkat kepekaan marker terhadap cahaya, jarak, gerakan, dan pengujian fungsi button.

1) Pengujian Cahaya: Pencahayaan berhubungan dengan intensitas cahaya dan jenis cahaya yang menerangi suatu objek. Pengujian ini dilakukan dengan memanfaatkan cahaya sebagai parameternya. Berdasarkan Tabel I, marker terdeteksi dalam kondisi pencahayaan cahaya terang outdoor dan masih dapat
TABEL I

PRNGUJIAN CAHAYA

\begin{tabular}{|c|l|l|}
\hline No. & Kondisi Cahaya & \multicolumn{1}{c|}{ Keterangan } \\
\hline $\mathbf{1}$ & Gelap & $\begin{array}{l}\text { Sistem tidak dapat mendeteksi } \\
\text { objek }\end{array}$ \\
\hline $\mathbf{2}$ & Cahaya lampu & Sistem dapat mendeteksi objek \\
\hline $\mathbf{3}$ & Cahaya matahari & Sistem dapat mendeteksi objek \\
\hline
\end{tabular}

mendeteksi beberapa objek pada kondisi cahaya indoor. Akan tetapi, pada kondisi gelap aplikasi tidak dapat membaca maupun mendeteksi marker. Hal ini disebabkan sistem deteksi marker bekerja berdasarkan pengolahan citra. Pada saat kondisi gelap atau intensitas cahaya gelap, degradasi warna yang terdeteksi memiliki derajat intensitas yang mendekati nol atau hitam.

2) Pengujian Jarak: Pengujian ini dilakukan untuk mengetahui batas jarak terjauh marker dapat membaca objek. Pengujian dilakukan dengan ketentuan sebagai berikut.

- Skala jarak sentimeter (cm).

- Marker dengan smartphone harus sejajar.

- Jarak yang diujikan adalah $10 \mathrm{~cm}, 15 \mathrm{~cm}, 20 \mathrm{~cm}, 25 \mathrm{~cm}$, $30 \mathrm{~cm}, 35 \mathrm{~cm}$, dan $40 \mathrm{~cm}$.

Hasil pengujian jarak terhadap tiga kondisi cahaya adalah sebagai berikut.

- Pada kondisi tanpa cahaya (gelap), marker tidak terbaca pada seluruh jarak yang diujikan.

- Pada kondisi cahaya lampu, sistem behasil mendeteksi marker pada jarak minimal $20 \mathrm{~cm}$ dan maksimal $35 \mathrm{~cm}$.

- Pada kondisi cahaya matahari, sistem berhasil mendeteksi marker pada jarak minimal $20 \mathrm{~cm}$ dan maksimal $35 \mathrm{~cm}$.

Persentase keberhasilan dan kegagalan dapat dihitung sebagai berikut.

Persentase Keberhasilan = $($ Keberhasilan $/$ Total Pengujian $) \times$ $100 \%$

Persentase Cahaya Gelap $=(0 / 49) \times 100 \%=0 \%$

Persentase Cahaya Lampu $=31 / 49 \times 100 \%=63,26 \%$

Persentase Cahaya Matahari $=30 / 49 \times 100 \%=61,22 \%$

Persentase Kegagalan $=100 \%$ - Persentase keberhasilan

Persentase Cahaya Gelap $=100 \%-0 \%=100 \%$

Persentase Cahaya Lampu $=100 \%-63,26 \%=36,74 \%$

Persentase Cahaya Matahari $=100 \%-61,22 \%=38,78 \%$

Dari data di atas, didapatkan hasil persentase keberhasilan dan kegagalan untuk kondisi-kondisi: a) tanpa cahaya (gelap) masing-masing sebesar $0 \%$ dan $100 \%$; b) pencahayaan dengan cahaya lampu masing-masing sebesar $63,26 \%$ dan $36,74 \%$; dan c) pencahayaan dengan cahaya matahari masing-masing sebesar $61,22 \%$ dan $38,78 \%$. Rekap hasil pengujian sistem berdasarkan kondisi cahaya ditunjukkan pada Gbr. 10.

3) Pengujian Delay: Pengujian ini dilakukan untuk mengetahui waktu sistem memunculkan objek AR. Dari hasil pengujian, didapatkan delay rata-rata yang ditunjukkan pada Tabel II.

4) Pengujian Gerakan: Gerakan juga memengaruhi proses sistem dalam mendeteksi suatu marker yang dipilih. Pengujian 


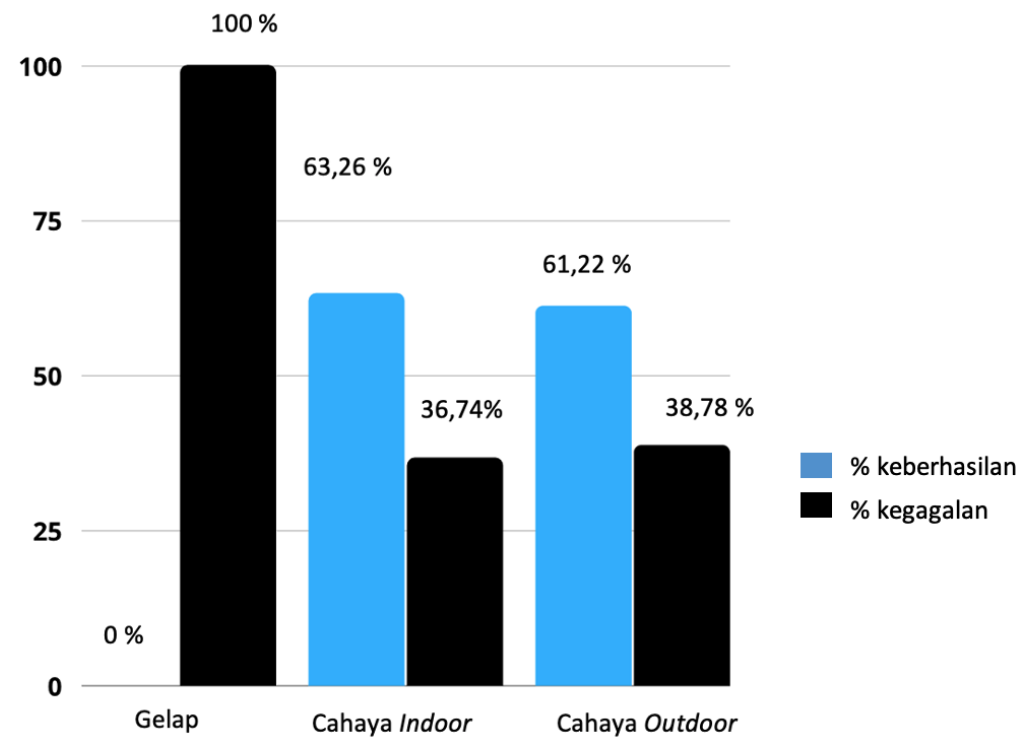

Gbr. 10 Grafik pengujian persentase keberhasilan dan kegagalan terhadap faktor cahaya.

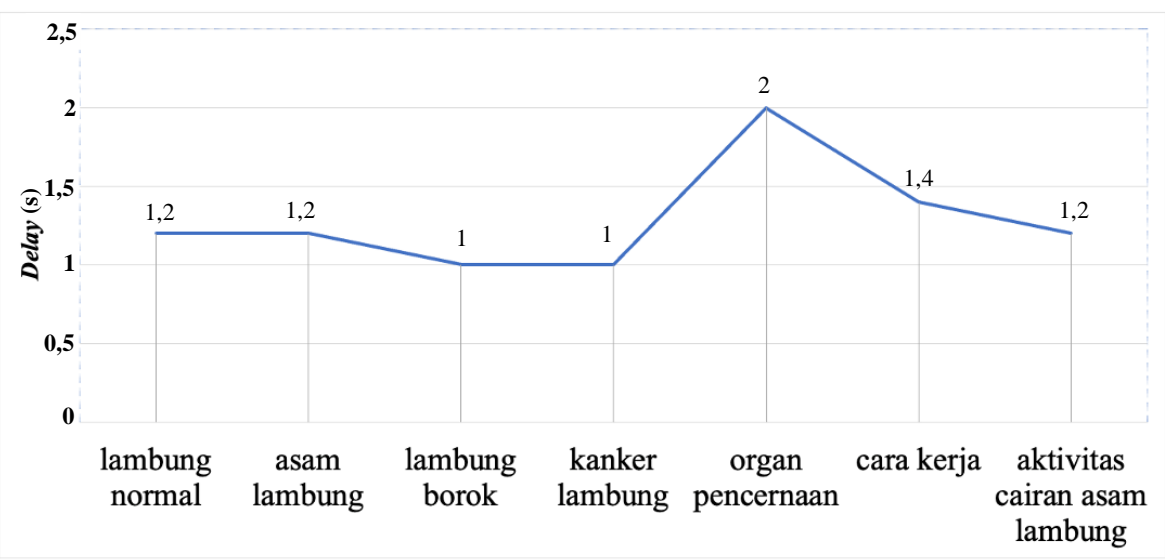

Gbr. 11 Fluktuasi delay akibat gerakan.

TABEL II

PRNGUJIAN DELAY

\begin{tabular}{|c|l|l|}
\hline No & Kondisi Cahaya & Rerata Delay \\
\hline $\mathbf{1}$ & Gelap & Tidak terdeteksi \\
\hline $\mathbf{2}$ & Cahaya lampu & 0,31 detik \\
\hline $\mathbf{3}$ & Cahaya matahari & 0,45 detik \\
\hline
\end{tabular}

gerakan dilakukan untuk mengetahui kepekaan sistem terhadap marker ketika kamera kehilangan dan menemukan marker yang akan diujikan, dengan marker digeser menjauhi dan mendekati kamera smartphone. Dengan melakukan pengujian ini, dapat diketahui marker masih dapat terdeteksi atau tidak. Berdasarkan hasil pengujian pada Gbr. 11, delay rata-rata akibat gerakan yang dihasilkan oleh sistem adalah 1,28 s dengan nilai delay tertinggi sebesar $2 \mathrm{~s}$ dan nilai delay terendah sebesar $1 \mathrm{~s}$.

5) Pengujian Marker AR: Pengujian ini dilakukan untuk mengetahui tingkat kemunculan objek jika marker tidak utuh. Dari percobaan yang telah dilakukan, marker tidak akan terbaca jika sebagian besar gambar marker tertutup. Hasil pengujian ditunjukkan pada Gbr. 12.
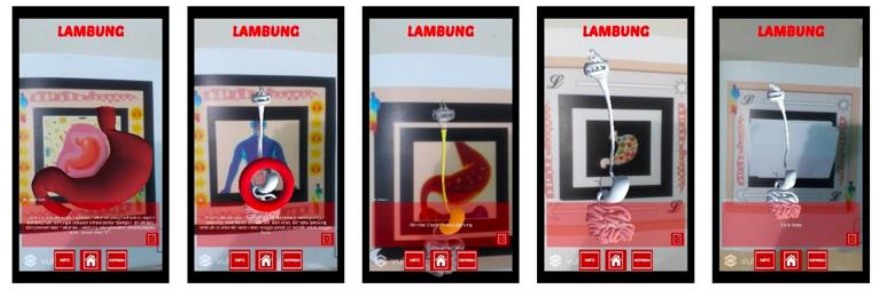

Gbr. 12 Berbagai kemunculan AR objek lambung yang salah jika marker tidak utuh.

6) Pengujian Fungsionalitas Button: Pengujian ini dimaksudkan untuk mengetahui fungsi button yang ada di aplikasi dapat berfungsi sebagaimana mestinya atau tidak. Berdasarkan lima kali pengujian terhadap semua button pada aplikasi, semua button menunjukkan persentase keberhasilan $100 \%$.

\section{B. Pengujian Survei Lapangan}

Pengujian survei lapangan dilakukan dengan menyebarkan kuesioner berupa beberapa pertanyaan mengenai fungsionalitas, kebermanfaatan, serta kemudahan penggunaan 


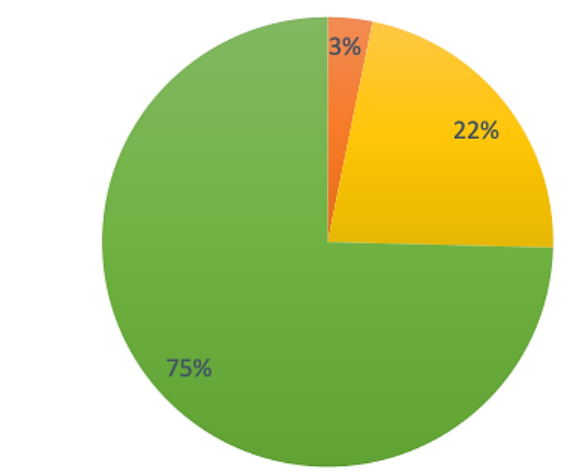

cukup puas $\square$ memuaskan $\square$ sangat memuaskan

(a)

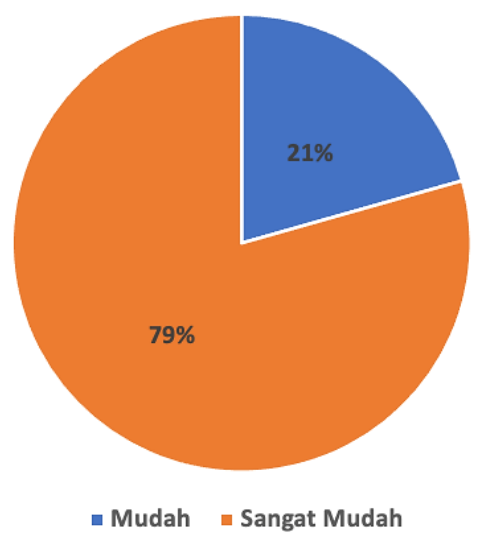

(b)

Gbr. 13 Diagram tingkat kepuasan pengguna aplikasi, (a) penilaian keseluruhan sistem, (b) penilaian kemudahan penggunaan sistem.

aplikasi. Kuesioner tersebut disebar kepada siswa SD, dan tercatat sebanyak 63 responden ikut serta dalam pengisian kuesioner. Dari data tersebut didapatkan hasil kepuasan pengguna dan tingkat kemudahan aplikasi bagi pengguna. Berdasarkan Gbr. 13, sebanyak 96,8\% responden memberi nilai memuaskan-sangat memuaskan dan $100 \%$ menilai aplikasi mudah-sangat mudah digunakan. Sementara itu, untuk penilaian kebermanfaatan, kuesioner mengenai aplikasi telah disebarkan kepada ahli pengajar. Dari 28 responden, sebanyak 96,4\% responden menyetujui bahwa aplikasi pembelajaran lambung ini dapat dijadikan media pembelajaran, dan sebanyak $100 \%$ menyetujui bahwa isi penjelasan, gambar, dan bentuk lambung telah sesuai.

\section{KESIMPULAN DAN SARAN}

Berdasarkan hasil pengujian, semua fungsi button pada aplikasi pembelajaran lambung bekerja dengan baik. Adapun akurasi deteksi marker dipengaruhi oleh beberapa parameter, di antaranya intensitas cahaya, jarak scan marker, dan pergerakan marker. Dari percobaan yang telah dilakukan terhadap jarak dan sudut, aplikasi paling baik digunakan ketika melakukan deteksi marker pada rentang jarak $20 \mathrm{~cm}$ sampai $35 \mathrm{~cm}$. Variasi yang timbul ini disebabkan oleh adanya perbedaan pengaturan letak pada saat perancangan sistem aplikasi. Pada cahaya gelap tidak terjadi delay karena objek tidak muncul, delay rata-rata yang dihasilkan sistem dengan intensitas cahaya lampu yaitu sebesar 0,31 s, dan delay rata-rata yang dihasilkan sistem dengan intensitas cahaya matahari sebesar $0,45 \mathrm{~s}$. Gerakan yang tidak stabil pada saat pemindaian juga dapat memengaruhi sistem ketika mendeteksi marker, sehingga sistem akan mencari lagi letak fokus dari marker agar dapat terdeteksi. Dari percobaan yang telah dilakukan, didapatkan nilai delay ratarata sebesar $1,28 \mathrm{~s}$. Selanjutnya, berdasarkan survei tingkat kepuasan pengguna, tercatat sebanyak $3,2 \%$ responden menjawab cukup puas, $22,2 \%$ responden menjawab puas, dan $74,6 \%$ responden menjawab sangat puas dengan adanya aplikasi pembelajaran lambung ini. Untuk tingkat kemudahan penggunaan, sebanyak $20,6 \%$ responden menjawab mudah dan $79,4 \%$ responden menjawab sangat mudah digunakan. Sementara itu, pada pengujian ahli, sebanyak 96,4\% menyetujui bahwa aplikasi pembelajaran lambung ini dapat dijadikan sebagai media pembelajaran dan $100 \%$ menyetujui bahwa isi penjelasan, gambar, dan bentuk lambung telah sesuai.

\section{REFERENSI}

[1] H. Ling, "Augmented Reality in Reality," IEEE Multimed., Vol. 24, No. 3, hal. 10-15, 2017.

[2] E.B. Setiawan dan R. Herdianto, "Penggunaan Smartphone Android sebagai Alat Analisis Kebutuhan Kandungan Nitrogen pada Tanaman Padi," J. Nas. Tek. Elektro dan Teknol. Inf., Vol. 7, No. 3, hal. 273-280, 2018.

[3] W. Li, A. Nee, dan S. Ong, "A State-of-the-Art Review of Augmented Reality in Engineering Analysis and Simulation," Multimodal Technol. Interact., Vol. 1, No. 3, hal. 1-22, Sep. 2017.

[4] H. Pratikno, "Kontrol Gerakan Objek 3D Augmented Reality Berbasis Titik Fitur Wajah dengan POSIT," J. Nas. Tek. Elektro dan Teknol. Inf., Vol. 4, No. 1, hal. 16-24, 2015.

[5] D. Mehta, M. Siddiqui, dan A. Javaid, "Facial Emotion Recognition: A Survey and Real-World User Experiences in Mixed Reality," Sensors, Vol. 18, No. 2, hal. 1-24, Feb. 2018.

[6] S. Ćuković, M. Gattullo, F. Pankratz, G. Devedžić, E. Carrabba, dan K Baizid, "Marker Based vs. Natural Feature Tracking Augmented Reality Visualization of the 3D Foot Phantom," Proc. Int. Conf. Electric. Biomed. Eng. Clean Energy and Green Comput., 2015, hal. 24-31.

[7] A.M. Ullah, M.R. Islam, S.F. Aktar, dan S.K.A. Hossain, "Remote-touch: Augmented Reality Based Marker Tracking for Smart Home Control," 2012 15th Int. Conf. Comp. Inf. Technol. (ICCIT), 2012, hal. 473-477.

[8] Z. Zainuddin, I.S. Areni, dan R. Wirawan, "Aplikasi Augmented Reality pada Sistem Informasi Smart Building," J. Nas. Tek. Elektro dan Teknol. Inf., Vol. 5, No. 3, hal. 1-6, 2016

[9] S. Aulia, R.Y. Purba, dan A. Gunarso, "Media Informasi untuk Bank Baterai Berbasis Augmented Reality," J. Nas. Tek. Elektro dan Teknol. Inf., Vol. 9, No. 3, hal. 254-260, 2020.

[10] A.M. Bachtiar dan A. Bardansyah, "Pembangunan Class Library untuk Domain Product Management di Aplikasi M-Commerce pada Android," J. Nas. Tek. Elektro dan Teknol. Inf., Vol. 6, No. 3, hal. 235-242, 2017.

[11] L.B. Kiat, M.B. Ali, N.D. Abd Halim, dan H.B. Ibrahim, "Augmented Reality, Virtual Learning Environment and Mobile Learning in Education: A Comparison," 2016 IEEE Conf. e-Learning, e-Management and e-Services (IC3e), 2016, hal. 23-28.

[12] A.K. Wahyudi, "ARca, Pengembangan Buku Interaktif Berbasis Augmented Reality dengan Smartphone Android," J. Nas. Tek. Elektro dan Teknol. Inf., Vol. 3, No. 2, hal. 96-102, 2014.

[13] T. Bratitsis, P. Bardanika, dan M. Ioannou, "Science Education and Augmented Reality Content: The Case of the Water Circle," 2017 IEEE 17th Int. Conf. Adv. Learning Technol. (ICALT), 2017, hal. 485-489.

[14] R. Budiawan, T.N. Damayanti, dan D.A. Nurmantris, "Pembelajaran Elektromagnetika Terapan Berbasis Augmented Reality: Kasus Sistem 
Koordinat," J. Nas. Tek. Elektro dan Teknol. Inf., Vol. 6, No. 4, hal. 436444, 2017.

[15] C. Juan, F. Beatrice, dan J. Cano, "An Augmented Reality System for Learning the Interior of the Human Body," 2008 Eighth IEEE Int. Conf. Adv. Learning Technol., 2008, hal. 186-188.

[16] C. Soto, M. Vargas, A. Uribe-Quevedo, N. Jaimes, dan B. Kapralos, "AR Stereoscopic 3D Human Eye Examination App," Proc. 2015 Int. Conf. Interact. Mob. Commun. Technol. Learn. (IMCL 2015), 2015, hal. 236238.

[17] H. Kolivand, A. El Rhalibi, M. Tajdini, S. Abdulazeez, dan P Praiwattana, "Cultural Heritage in Marker-Less Augmented Reality: A Survey," dalam Advanced Methods and New Materials for Cultural Heritage Preservation, D. Turcanu-Carutiu, R.-M. Ion, Eds., London, Inggris: IntechOpen, 2019, hal. 1-19.

[18] J.C.P. Cheng, K. Chen, dan W. Chen, "Comparison of Marker-Based and
Markerless AR: A Case Study of an Indoor Decoration System," Lean Comput. Construction Congress - Volume 1: Proc. Joint Conf. Comput. Construction, 2017, hal. 483-490.

[19] D.K. Baroroh dan R. Ramadhan, "Perancangan Alat Bantu Analisis Rapid Entire Body Assessment (REBA) Berbasis Aplikasi Android," J. Nas. Tek. Elektro dan Teknol. Inf., Vol. 7, No. 3, hal. 266-272, 2018.

[20] M. Mekni dan A. Lemieux, "Augmented Reality: Applications, Challenges and Future Trends," Proc. 13th Int. Conf. Appl. Comput. Appl. Computational Sci. (ACACOS '14), 2014, hal. 205-214.

[21] I.R. Daniels dan W.H. Allum, "The Anatomy and Physiology of the Stomach," dalam Upper Gastrointestinal Surgery, J.W.L. Fielding dan M.T. Hallissey, Eds., London, Inggris: Springer, 2005, hal. 17-37.

[22] J. Maret-Ouda, S.R. Markar, dan J. Lagergren, “Gastroesophageal Reflux Disease," JAMA, Vol. 324, No. 24, hal. 2536-2547, Des. 2020. 